\title{
Persian Adaptation of Actionable Bladder Symptom Screening Tool Among Patients with Multiple Sclerosis
}

This article was published in the following Dove Press journal: Journal of Multidisciplinary Healthcare

\author{
Mohaddeseh Azadvari ${ }^{1}$ \\ Abdorreza Naser Moghadasi' \\ Amir Reza Azimi' \\ Farzaneh Sharifiaghdas ${ }^{2}$ \\ Seyede Zahra Emami Razavi $\mathbb{D D}^{\prime}$ \\ Sharareh Eskandarieh' \\ Maryam Hosseini' \\ Shahram Rahimi-Dehgolan (1) ${ }^{\prime}$ \\ Mohammad Ali Sahraian (D) ' \\ 'Multiple Sclerosis Research Center, \\ Neuroscience Institute, Tehran University \\ of Medical Sciences, Tehran, I. R. of Iran; \\ 2Urology Department, Shahid \\ Labbafinejad Hospital, Urology \\ Nephrology Research Center (UNRC), \\ Shahid Beheshti University of Medical \\ Science(SBMU), Tehran, I. R. of Iran
}

Correspondence: Seyede Zahra Emami Razavi

Tel +982161192291

Fax +98 21 66581604

Email zemamirazavi@gmail.com
Purpose: Multiple sclerosis (MS) is the most neurologic disease among individuals of $20-45$ years. About $75 \%$ of MS patients report bladder problems that have a moderatehigh impact on their life. The present study aimed to translate and determine the validity and reliability of the Persian version of ABSST questionnaire.

Methods: The standard validation process for preparing the Persian version of ABSST was performed by means of an expert committee. After a pilot study and confirming the harmonized translated form, we tested the final version of questionnaire on 40 patients with a definite diagnosis of MS symptoms, once at the baseline and another after two weeks in order to prevent recall-induced agreement. Test-retest reliability was calculated as Spearman's correlation coefficient. Also, content validity indices (CVIs), as well as internal consistency were analyzed in STATA.

Results: Forty participants with a mean age of 38.8 years were included in this study. Only $20 \%$ of them were male. The Persian version achieved a good internal consistency with a Cronbach- $\alpha$ value of 0.91 , relatively similar to the original version. The coefficients for measuring the correlation between each item score with the total score of our questionnaire were between $0.58-0.89$. This value confirmed an appropriate validity for the Persian version of ABSST. Regarding test-retest reliability assessment, total Spearman's coefficient was 0.85 ; with 0.84 for the severity of symptoms and 0.87 for the impact of urologic disorders on patients`social life.

Conclusion: The current findings proved that this accurate questionnaire could be used to investigate urinary symptoms among Persian-speaking MS patients.

Keywords: reliability studies, reliability, questionnaires, urinary symptoms, multiple sclerosis

\section{Introduction}

Multiple Sclerosis (MS) is a demyelinating disorder of the central nervous system (CNS). It is the most neurologic disease among individuals of 20-45 years. A widespectrum of signs and symptoms might occur due to different loci of white matter plaques. ${ }^{1-4}$ Urinary problems are among the most important symptoms in MS patients. ${ }^{5-7}$ These problems include frequency and/or urgency of urination, hesitancy in starting urination, frequent nighttime urination (nocturia), ${ }^{8}$ urinary incontinence, and inability to empty the bladder completely. ${ }^{1}$ About $75 \%$ of MS subjects report urinary symptoms that have moderate to high impact on their life. Despite high prevalence of condition, many patients usually fail to talk about their urinary 
problems. ${ }^{9}$ In fact, a large survey found that only $8 \%$ of sufferers mentioned their symptoms. ${ }^{10}$ There are a few numbers of screening tools for urinary disorders. ${ }^{5-7}$ The Actionable Bladder Symptoms Screening Tool (ABSST) questionnaire is one of those which researchers advocate because of its brief and easy-to-use items. The ABSST was first developed to identify urinary symptoms, in order to screen MS patients who had corresponding problems. ${ }^{11}$ It includes items such as symptoms, coping strategies, and the effects of these symptoms on MS patients. Indeed, ABSST could facilitate communication between physicians and MS patients throughout describing their urinary symptoms. ${ }^{11}$

The reliability and validity of ABSST questionnaire had been previously determined among English-speaking patients with overactive bladder. ${ }^{12}$ Considering an increasing incidence of MS among Persian population with annual percentage change of $12 \%$ during last decade; ${ }^{13,14}$ and also due to the large psychosocial impact of urinary symptoms, the present study aimed to translate and determine the validity and reliability of Persian version of ABSST questionnaire. In this way, physicians would be able to use an accurate, practical and rapid screening tool based on patients' reported symptoms to facilitate the evaluation of urinary disorders in affected MS patients.

\section{Methods}

Among patients presented to neurology clinic of MS center in Sina hospital, a tertiary referral center, of Tehran from June 2017 to the November 2017, 58 consequent subjects were enrolled. After explaining the methodology and excluding ineligible patients, 40 participants were included. Only subjects at the age of 20-50 years, who had a definite diagnosis of MS according to the 2017 revised McDonald MS diagnostic criteria for at least six months that have good cognitive state, vision and motor function in hand with EDSS $<7$, were studied. Exclusion criteria were: Active phase of the disease, ongoing UTI, history of pelvic floor trauma or urologic surgery and any other major disease such as diabetes mellitus, hypertension. Written informed consent was obtained in accordance with the Declaration of Helsinki. This study approve by this number IR.TUMS.VCR.REC.1397.1104 in ethic committee of Tehran medical university.

The original ABSST questionnaire (Appendix-1) consisted of eight items; the first five questions were about micturition frequency, leakage, urgency, and nocturnal voiding; while another three items evaluated the impact of mentioned symptoms on patients` function on the work environment, social relationships, and embarrassment. The ABSST has a 4-point Likert scale (from 0-3; where 0 indicates no symptoms or impact; and 3 represent severe symptoms or large impact). The total ABSST score was calculated as the number of questions that patient had a serious problem (responses inside the blue section; Appendix-1). Therefore, total scores ranged from $0-8$; a score of $>3$ indicated a need for urological referral. ${ }^{2}$ The standard validation process was performed in four separatesteps. At first: the original English version was translated to Persian by two experienced bilingual translators. Secondly: they back-translated it to English; then the grammatical and semantic evaluation was done between two versions to assure that the original content was preserved. Then a final Persian questionnaire was provided by a committee of 12 experts including two translators, three physiatrists, three MS Fellowship, three urologists, and an epidemiologist. All 12 experts rated comments about the relevance, simplicity, and clarity of ABSST items were analyzed and expressed as three content validity indices (CVI-R for relevancy; CVI-S for simplicity; CVI-C for clarity of questions). ${ }^{15}$ Afterwards, in a pilot study, we administered the harmonized Persian version of ABSST to 10 participants. Almost all of them stated that ABSST was easy to fill out. Eventually, we tested the final version of the questionnaire (Appendix-2) among 40 patients with definite MS. Participants filled out the translated ABSST questionnaire, once at the baseline and another after two weeks in order to prevent recall-induced agreement.

Only data gathered from the entire population was analyzed and the pilot sample was not quantitatively evaluated. To confirm the properties of ABSST items, STATA ${ }^{\circledR}$ package version 11 was utilized. The descriptive findings were expressed as mean, standard deviation (SD), and relative frequency. Also, since the data did not show normal distribution, test-retest reliability was calculated as Spearman's rank correlation. Psychometric validity was expressed as the aforementioned three indices, as well as content validity ratio (CVR). Moreover, internal consistency reliability was measured using Cronbach $\alpha$ coefficient. A p value less than 0.05 was considered as the significant level.

\section{Results}

A total of 40 participants with a mean age of $38.88 \pm 9.0$ years, were enrolled in this study. The average value of BMI was $25.27 \pm 5.3 \mathrm{~kg} / \mathrm{m}^{2}$, respectively. Other demographics have been described in Table 1. Eighty percent of 
Table I Baseline Characteristics of Participants

\begin{tabular}{|c|c|c|}
\hline Variable & Status & Number (Frequency \%) \\
\hline Gender & $\begin{array}{l}\text { Male } \\
\text { Female }\end{array}$ & $\begin{array}{l}8(20 \%) \\
32(80 \%)\end{array}$ \\
\hline Marital Status & $\begin{array}{l}\text { Married } \\
\text { Single } \\
\text { Divorced } \\
\text { Widow }\end{array}$ & $\begin{array}{l}28(70 \%) \\
9(22.5 \%) \\
2(5 \%) \\
I(2.5 \%)\end{array}$ \\
\hline $\begin{array}{l}\text { Educational } \\
\text { Level }\end{array}$ & $\begin{array}{l}\text { Under the diploma } \\
\text { Diploma } \\
\text { University } \\
\text { education }\end{array}$ & $\begin{array}{l}5(12.5 \%) \\
19(47.5 \%) \\
18(45 \%)\end{array}$ \\
\hline Job & $\begin{array}{l}\text { Housewife } \\
\text { Unemployed } \\
\text { Employee } \\
\text { Worker } \\
\text { Student }\end{array}$ & $\begin{array}{l}2 \text { I (52.5\%) } \\
2(5 \%) \\
\text { I4 (35\%) } \\
\text { I }(2.5 \%) \\
2(5 \%)\end{array}$ \\
\hline
\end{tabular}

the patients were female. Seventy percent were married, and about $40 \%$ were university graduated.

\section{Validity}

The content validity of ABSST questionnaire has been presented in Table 2. All calculated CVRs were between $0.66-1$. For the participation of 12 persons in the expert panel, $\mathrm{CVR}=0.56$ was considered as the minimum. Then it would be concluded that all eight items of the questionnaire were acceptable. The content validity indices (CVI) for most items were above 0.75 . The overall CVI for the entire questionnaire was $0.91,0.86$, and 0.92 in regard to relevancy, simplicity, and clarity, respectively. Also, the face validity of the Persian version was acceptable, since almost all of patients filling out the questionnaire stated that ABSST was easy and could be administered in a short time. Moreover, the result of existing correlation between each item with total score has been demonstrated. All eight items had a significant and direct correlation with total score of the tool [Table 3].

\section{Reliability}

The Cronbach $\alpha$ coefficient for the Persian version of ABSST was 0.91 that confirmed the internal consistency. Spearman`s rank coefficients were 0.84 and 0.87 for two subscales of symptoms severity and their impact, respectively; with the total amount of 0.91 (p-value $<0.0001$ ). Also, the intra-class correlation coefficient (ICC) was 0.86 ,
Table 2 Results of Content Validity for the Persian Version of ABSST

\begin{tabular}{|c|c|c|c|c|c|}
\hline No. & Questions & C-CVI & S-CVI & R-CVI & CVR \\
\hline I & $\begin{array}{l}\text { How many times did } \\
\text { you need urinary } \\
\text { excretion during } \\
\text { the day? }\end{array}$ & 0.83 & 0.75 & 0.91 & 0.66 \\
\hline 2 & $\begin{array}{l}\text { How often do you find } \\
\text { urine leakage? }\end{array}$ & 0.83 & 0.75 & 0.75 & 0.91 \\
\hline 3 & $\begin{array}{l}\text { How strong was your } \\
\text { urge to empty urine } \\
\text { during the day? }\end{array}$ & 0.75 & 0.83 & 0.83 & 0.83 \\
\hline 4 & $\begin{array}{l}\text { How many times did } \\
\text { you wake up in } \\
\text { a normal night? }\end{array}$ & 1 & 0.91 & 0.91 & I \\
\hline 5 & $\begin{array}{l}\text { How many times have } \\
\text { you been urinating } \\
\text { during a normal day? }\end{array}$ & I & 0.91 & I & I \\
\hline 6 & $\begin{array}{l}\text { To what extent have } \\
\text { your activities and } \\
\text { relationships with } \\
\text { friends and family been } \\
\text { limited because of } \\
\text { bladder problems? }\end{array}$ & I & 0.91 & 1 & I \\
\hline 7 & $\begin{array}{l}\text { How embarrassed are } \\
\text { you due to your } \\
\text { urinary problems? }\end{array}$ & 1 & I & 1 & I \\
\hline 8 & $\begin{array}{l}\text { How much have your } \\
\text { outdoor activities } \\
\text { (volunteer or job) } \\
\text { been limited because } \\
\text { of bladder problems? } \\
\text { Mean validity }\end{array}$ & 0.92 & 0.86 & 0.91 & 0.9 \\
\hline
\end{tabular}

Abbreviations: $\mathrm{C}-\mathrm{CVI}=$ Content Validity Index for Transparency; S-CVI = Content validity index for simplicity; $\mathrm{R}-\mathrm{CVI}=$ Validity Approximation Index; $\mathrm{CVR}=$ Content Validity Ratio.

again indicating excellent test-retest reliability for the Persian version of ABSST [Table 4].

\section{Discussion}

In the present study, 40 MS subjects were included; the majority was females. The Persian version revealed a good agreement, near to that of the original version. Generally, this survey confirmed an appropriate validity and acceptable reliability for the Persian version of ABSST in the review of urinary disorders among patients with MS. Cronbach $\alpha$ coefficient was calculated as 0.91 , which 
Table 3 Correlation of Each Item with Total ABSST Score

\begin{tabular}{|c|c|c|c|}
\hline No. & Questions & $\begin{array}{l}\text { Cronbach } \\
\alpha \text { if Item Is } \\
\text { Deleted }\end{array}$ & $\begin{array}{l}\text { Corrected } \\
\text { Correlation } \\
\text { for Each Item }\end{array}$ \\
\hline I & $\begin{array}{l}\text { How many times did you } \\
\text { need urinary excretion } \\
\text { during the day? }\end{array}$ & 0.90 & 0.73 \\
\hline 2 & $\begin{array}{l}\text { How often do you find } \\
\text { urine leakage? }\end{array}$ & 0.90 & 0.81 \\
\hline 3 & $\begin{array}{l}\text { How strong was your urge } \\
\text { to empty urine during } \\
\text { the day? }\end{array}$ & 0.90 & 0.76 \\
\hline 4 & $\begin{array}{l}\text { How many times did you } \\
\text { wake up in a normal night? }\end{array}$ & 0.90 & 0.76 \\
\hline 5 & $\begin{array}{l}\text { How many times have you } \\
\text { been urinating during } \\
\text { a normal day? }\end{array}$ & 0.91 & 0.58 \\
\hline 6 & $\begin{array}{l}\text { To what extent have your } \\
\text { activities and relationships } \\
\text { with friends and family } \\
\text { been limited because of } \\
\text { bladder problems? }\end{array}$ & 0.89 & 0.87 \\
\hline 7 & $\begin{array}{l}\text { How embarrassed are you } \\
\text { due to your urinary } \\
\text { problems? }\end{array}$ & 0.89 & 0.87 \\
\hline 8 & $\begin{array}{l}\text { How much have your } \\
\text { outdoor activities } \\
\text { (volunteer or job) been } \\
\text { limited because of bladder } \\
\text { problems? }\end{array}$ & 0.89 & 0.89 \\
\hline
\end{tabular}

was relatively similar to the original $(\alpha=0.95)$ version. ${ }^{11}$ The coefficients for measuring the correlation between each item with the total score were between $0.58-0.89$; which discovered an appropriate internal consistency for the Persian form of ABSST. Current findings are in accordance with an earlier study on 2014, conducted to assess the validity and reliability of the English version. ${ }^{12}$ The Cronbach $\alpha$ coefficient was reported as 0.9 in that research, and the correlation coefficients of items with total score were all between $0.28-0.81 .^{12}$ In the present version, the correlation between items was determined using Spearman`s rank coefficient, which was 0.84 for the severity of urinary symptoms and 0.87 for the impact of the urologic disorder on patients' social life. This coefficient was 0.85 in total, approximately near to the original (p-value $=0.782$ ) version. ${ }^{11}$
Table 4 Internal Consistency, Reliability and Test-Retest Reliability for the Persian ABSST Questionnaire

\begin{tabular}{|l|l|l|l|}
\hline & Mean \pm SD & $\begin{array}{l}\text { Spearman`s } \\
\text { Coefficient }\end{array}$ & $\begin{array}{l}\text { Cronbach } \alpha \\
\text { Coefficient }\end{array}$ \\
\hline $\begin{array}{l}\text { Severity of urinary tract } \\
\text { disorder }\end{array}$ & $10.45 \pm 3.28$ & 0.84 & 0.83 \\
\hline $\begin{array}{l}\text { Impact of urinary } \\
\text { dysfunction on social life }\end{array}$ & $4.75 \pm 2.78$ & 0.87 & 0.95 \\
\hline Total & $15.20 \pm 5.38$ & 0.85 & 0.91 \\
\hline
\end{tabular}

Abbreviation: $\mathrm{SD}=$ standard deviation.

The present study aimed to translate and determine the validity and reliability of the Persian version of the ABSST questionnaire. In this way, it would be possible to use a reliable, accurate, practical and rapid implementation tool based on the patient's reported symptoms to facilitate the evaluation of overactive urinary disorders in affected patients. There are various screening tools for urinary disorders. The ABSST questionnaire has been selected because of the low number of questions and ease of completion by the patients, as well as attention focused on overactive bladder symptoms. The latter is the most common urinary tract disorder diagnosed among MS patients. The current questionnaire also evaluates the effect of urinary symptoms on the patient's quality of life and function. This is a useful screening for physicians to detect urinary symptoms in MS patients who may be in need of treatment for lower urinary tract (LUT) symptoms related to the disease. Occasionally, referral to the urologist is delayed, which causes the symptoms to become more severe. ABSST offers valuable benefits to both neurologists and urologists. In this case, Persian questionnaire can help the physician to control the condition and manage the corresponding costs by earlier treatment.

The shortcomings of the present study include the lack of patients' co-operation due to the misunderstanding of validation methodology, which cause some drop out during test-the retest evaluation. These limitations could be addressed in future studies by providing patients' guide to the methodology and the beneficial effects of this research on improving their quality of life. Another limitation was the lack of a parallel gold standard test to assess the prediction performance of ABSST questionnaire. Based on the original version scores, ${ }^{11}$ ABSST could be used as a screening tool for detection of LUTdisorders among MS patients, with a minimum score $=3$, as the cut-off point. 
Therefore, further studies are needed to determine sensitivity, specificity, and overall accuracy of this translated version at different cut-off points.

\section{Conclusion}

The present study proved that a valid and reliable version of ABSST questionnaire could be used to investigate LUT symptoms among Persian-speaking MS patients.

\section{Acknowledgments}

The authors want to thank authorities of Tehran University of Medical Sciences for their comprehensives support for this study and also thank Ms. Taktem Firoozi for helping us in data gathering of this study.

\section{Disclosure}

The authors of this article declare that they have no conflict of interests.

\section{References}

1. Noseworthy JH, Lucchinetti C, Rodriguez M, et al. Multiple sclerosis. $N$ Engl J Med. 2000;343(13):938-952. doi:10.1056/NEJM200009283 431307

2. Compston A, Coles A. Multiple sclerosis. Lancet. 2002;359 (9313):1221-1231. doi:10.1016/S0140-6736(02)08220-X

3. Lew-Starowicz M, Rola R. Prevalence of sexual dysfunctions among women with multiple sclerosis. Sex Disabil. 2013;31(2):141-153. doi:10.1007/s11195-013-9293-9
4. Borello-France D, Leng W, O'Leary M, et al. Bladder and sexual function among women with multiple sclerosis. Mult Scler. 2004;10 (4):455-461. doi:10.1191/1352458504ms1060oa

5. de Seze M, Ruffion A, Denys P, et al. The neurogenic bladder in multiple sclerosis: review of the literature and proposal of management guidelines. Mult Scler. 2007;13(7):915-928. doi:10.1177/135 2458506075651

6. Pappalardo A, Patti F, Reggio A. [Management of neuropathic bladder in multiple sclerosis]. Clin Ter. 2004;155(5):183-186.

7. Sammarco A, Mahajan S. The bladder in MS: a review. $J$ Neurol Neurophysiol. 2014;5:200. doi:10.4172/2155-9562.1000200

8. Nakipoglu GF, Kaya AZ, Orhan G, et al. Urinary dysfunction in multiple sclerosis. J Clin Neurosci. 2009;16(10):1321-1324. doi:10.1016/j.jocn.2008.12.012

9. Brucker BM, Nitti VW, Kalra S, et al. Barriers experienced by patients with multiple sclerosis in seeking care for lower urinary tract symptoms. Neurourol Urodyn. 2017;36(4):1208-1213. doi:10. 1002/nau.23101

10. Kommunikation K Nordic survey on urinary dysfunction 2011-2012. Available from: http://nikola.nu/sites/all/files/documents/natverk/2nor disk_undersokning_sinoba.pdf. Accessed November 17, 2018.

11. Burks J, Chancellor M, Bates D, et al. Development and validation of the actionable bladder symptom screening tool for multiple sclerosis patients. Int J MS Care. 2013;15(4):182-192. doi:10.7224/1537-2073.2012-049

12. Cardozo L, Staskin D, Currie B, et al. Validation of a bladder symptom screening tool in women with incontinence due to overactive bladder. Int Urogynecol J. 2014;25(12):1655-1663. doi:10.1007/ s00192-014-2417-7

13. Eskandarieh S, Heydarpour P, Elhami S-R, et al. Prevalence and incidence of multiple sclerosis in Tehran, Iran. Iran $J$ Public Health. 2017;46(5):699-704.

14. Samadzadeh S, Tabibian E, Sabokbar T, et al. HLA-DRB1 does not have a role in clinical response to interferon-beta among Iranian multiple sclerosis patients. J Neurol Sci. 2015;352(1-2):37-40. doi:10.1016/j.jns.2015.03.004

15. Waltz CF. Nursing Research: Design Statistics and Computer Analysis. F.A. Davis Company; 1981.
Journal of Multidisciplinary Healthcare

\section{Publish your work in this journal}

The Journal of Multidisciplinary Healthcare is an international, peerreviewed open-access journal that aims to represent and publish research in healthcare areas delivered by practitioners of different disciplines. This includes studies and reviews conducted by multidisciplinary teams as well as research which evaluates the results or conduct of such teams or healthcare processes in general. The journal covers a very wide range of areas and welcomes submissions from practitioners at all levels, from all over the world. The manuscript management system is completely online and includes a very quick and fair peer-review system. Visit http://www.dovepress.com/testimonials. php to read real quotes from published authors. 